\title{
Cefditoren: Comparative efficacy with other antimicrobials and risk factors for resistance in clinical isolates causing UTIs in outpatients
}

Despina Hatzaki ${ }^{1}$, Garyphallia Poulakou ${ }^{2 *}$, Ioannis Katsarolis ${ }^{2}$, Niki Lambri ${ }^{2}$, Maria Souli², Ioannis Deliolanis ${ }^{3}$, Georgios K Nikolopoulos ${ }^{4}$, Evangelia Lebessi ${ }^{1}$ and Helen Giamarellou ${ }^{2,5}$

\begin{abstract}
Background: To investigate a possible role of Cefditoren, a recently marketed in Greece third-generation oral cephalosporin in urinary infections of outpatients.

Methods: During a multicenter survey of Enterobacteriaceae causing UTIs in outpatients during 2005-2007, Cefditoren MICs were determined by agar dilution method in a randomly selected sample of uropathogens. Susceptibility against 18 other oral/parenteral antimicrobials was determined according to Clinical and Laboratory Standards Institute methodology.

Results: A total of 563 isolates (330 Escherichia coli, 142 Proteus mirabilis and 91 Klebsiella spp) was studied; MIC50/ MIC90 of Cefditoren was 0.25/0.5 mg/L respectively, with $97.1 \%$ of the isolates being inhibited at $1 \mathrm{mg} / \mathrm{L}$. All 12 strains producing ESBLs or AmpC enzymes were resistant to cefditoren. Susceptibility rates (\%) for amoxicillin/ clavulanic acid, cefuroxime axetil, cefotaxime, ciprofloxacin, trimethoprim/sulfamethoxazole and fosfomycin were 93.1- 94.1-96.8-93.1-71.9 and 92.8\% respectively. Cefditoren MIC was significantly higher in nalidixic/ciprofloxacin non-susceptible strains; resistance to cefditoren was not associated with resistance to mecillinam, fosfomycin nitrofurantoin and aminoglycosides. Multivariate analysis demonstrated history of urinary infection in the last two weeks or three months as risk factors for cefditoren resistance.
\end{abstract}

Conclusions: Cefditoren exhibited enhanced in vitro activity against the most common uropathogens in the outpatient setting, representing an alternative oral treatment option in patients with risk factors for resistance to first-line antibiotics.

Keywords: Urinary tract infections, Acute uncomplicated cystitis, Cephalosporins, Antimicrobial resistance, Empirical treatment

\section{Background}

Urinary tract infections (UTIs) represent the most frequent bacterial infection encountered in the community setting being caused in their vast majority by members of the family of Enterobacteriaceae [1,2]. Recently, antimicrobial resistance among uropathogens causing uncomplicated cystitis has increased, as well as the recognition of the importance of the ecological adverse

\footnotetext{
* Correspondence: gpoulakou@gmail.com

${ }^{2} 4$ th Department of Internal Medicine and Infectious Diseases Research Laboratory, Athens University School of Medicine, 1, Rimini St, 12462 Haidari, Athens, Greece

Full list of author information is available at the end of the article
}

effects of antimicrobial therapy (collateral damage) [2-6]. Effective empirical therapy must be based on susceptibility profiles of the uropathogens, therefore surveillance studies are important tools to guide antibiotic selection [3]. However, in a "real-life" scenario, empirical therapy is most likely to be prescribed either without a urine culture or before the results become available. A recognized drawback of many published studies is the inclusion of strains collected from hospitals, thus limiting surveillance in populations with easy access to tertiary centers even as outpatients. Additionally, in several laboratorybased studies no distinction could be safely made between complicated and uncomplicated UTIs; that same

\section{Ciomed Central}


is true for purely "community" infections and nosocomial or healthcare-associated infections that are being treated in the community $[3,6]$.

Cefditoren is a third generation oral cephalosporin with a broad spectrum of activity comprising Gram-positive and Gram-negative bacterial species [7,8]. After an oral 400-mg single dose, the mean concentrations in urine are $186.5 \mathrm{mg} / \mathrm{L}$ at 2 to $4 \mathrm{~h}$ and $12.7 \mathrm{mg} / \mathrm{L}$ at 8 to $12 \mathrm{~h}$; available data have shown its potential to be used in the treatment of UTIs [9]. Cefditoren retained activity against some clinically significant pathogens harboring $\beta$-lactamase enzymes. In a study by Sevillano et al., cefditoren exhibited bactericidal activity ( $>4 \log 10$ reduction) against TEM-1 (penicillinase production or hyperproduction) and TEM-34 derivative (IRT-6) isolates from 4 to $24 \mathrm{~h}$. However, against ESBL-producing strains, no sustained bactericidal activity was demonstrated: against strains harboring the SHV determinant bactericidal activity was achieved only in the 6- to 8-h whereas against the TEM-116 strain a 2 - $\log 10$ regrowth occurred from 12 to $24 \mathrm{~h}$ [9].

The present study was conducted in order to investigate a possible role of cefditoren in the treatment of UTIs treated in the outpatient setting. Given the expanded spectrum of cefditoren, strains of uncomplicated as well as complicated UTIs were included.

\section{Methods}

\section{Study period and participating institutions}

From January 2005 to March 2007 a Greek multicentre surveillance network was formed by private or public microbiology laboratories, representative of the whole country, in order to obtain Enterobacteriaceae isolates from outpatients with UTI. Personal data were collected anonymously. The research protocol was approved by the Ethics Committees of the cooperating hospitals, namely "Attikon" University General Hospital of Athens, "Sismanoglion" General Hospital of Athens and "G. Gennimatas" General Hospital of Athens. Primary care centers and Private Institutions participating in this study do not have Ethics Committees. Isolated strains were shipped to the central laboratory (Laboratory for Infectious Diseases and Antimicrobial Chemotherapy, 4th Dept of Internal Medicine, Athens University School of Medicine, University General Hospital ATTIKON). The network's structure and methodology have been reported previously [10].

\section{Bacterial isolates}

A single urine culture per outpatient referred for a urine sample culture to each collaborating centre was collected along with a detailed questionnaire tracking demographic and clinical information. Clinical data included: reason for giving a urine sample, symptoms, history of UTI (in the last 2 weeks, 3 months or in the previous year prior to sampling), recent use of antibiotics (in the previous 2 weeks and 3 months), history of admission to the hospital and/or insertion of a urinary catheter during the previous year, presence of diabetes mellitus, nephrolithiasis, presence of urinary catheter and pregnancy on sampling [10]. A culture was considered positive with a growth of a single microorganism $>10^{4} \mathrm{CFU} / \mathrm{ml}$. Bacterial isolates were identified by biochemical profiling using API systems (BioMerieux, Basingstoke, UK).

Isolates included in the current study were randomly selected from the total collection, which included 2446 microorganisms, 2280 of them being either E. coli, or Proteus mirabilis or Klebsiella spp. As defined by the study protocol every fourth isolate per center was selected for the cefditoren study; 7 isolates were dropped out due to contamination.

\section{Antimicrobial susceptibility testing}

Antimicrobial susceptibility testing to all antibiotics except Cefditoren was performed using the disk diffusion method, according to the Clinical Laboratory Standard Institute recommendations, CLSI 2011 [11]. Antimicrobials tested (disks) were: Ampicillin $(10 \mu \mathrm{g})$, Cephalothin $(30 \mu \mathrm{g})$, Cefuroxime $(30 \mu \mathrm{g})$, Cefotaxime $(30 \mu \mathrm{g})$, Ceftazidime $(30 \mu \mathrm{g})$, Amoxicillin/Clavulanic acid $(20 / 10 \mu \mathrm{g})$, Piperacillin/tazobactam (100/10 $\mu \mathrm{g})$, Ticarcillin/clavulanate $(75 / 10 \mu \mathrm{g})$, Imipenem $(10 \mu \mathrm{g})$, Ciprofloxacin $(5 \mu \mathrm{g})$, Trimethoprim/Sulfamethoxazole $(1.25 / 23.75 \mu \mathrm{g})$, Nalidixic acid $(30 \mu \mathrm{g})$, Nitrofurantoin $(300 \mu \mathrm{g})$, Fosfomycin $(200 \mu \mathrm{g})$, Mecillinam $(10 \mu \mathrm{g})$, Gentamicin $(10 \mu \mathrm{g})$, Amikacin $(30 \mu \mathrm{g})$, Netilmicin $(30 \mu \mathrm{g})$. Additionally, in view of the widespread use of quinolones in our community, MICs for Ciprofloxacin were determined by E-test method (AB-Biodisk, Solna, Sweden), in order to obtain a depiction of resistance trends within the susceptibility range in our population.

Susceptibility to Cefditoren was tested by agar dilution method, according to CLSI 2011 methodology. Escherichia coli ATCC 25922 was used as a quality control microorganism and was included in each run. Cefditoren standard powder was supplied by GlaxoSmithKline (Hellas). In lack of CLSI or EUCAST established breakpoints for Cefditoren, isolates with MIC $\leq 1 \mathrm{mg} / \mathrm{L}$ were considered as sensitive according to the recent literature [12-14]. This choice was further supported by the recent EUCAST clinical breakpoints for third generation cephalosporins against Enterobacteriaceae [15].

Phenotypic identification of extended-spectrum $\beta$-lactamases (ESBL) production was confirmed following the CLSI (2011) guidelines [11]. Phenotypic identification of plasmidic AmpC $\beta$-lactamases was additionally tested using the phenyl boronic acid inhibition method, as described previously [16]. Other mechanisms of resistance (production of inhibitor-resistant TEM [IRT] $\beta$ - 
Table 1 Demographic and clinical data per type of infection (for $\mathbf{3 3 4}$ cases out of the total $\mathbf{5 6 3}$ studied)

\begin{tabular}{|c|c|c|}
\hline & $\begin{array}{l}\text { Pts with } \\
\text { AUC (\%) }\end{array}$ & $\begin{array}{l}\text { Total patients } \\
\text { sample with } \\
\text { available clinical } \\
\text { information }\end{array}$ \\
\hline No of patients (\% of total) & $172(51.5)$ & $334(100)$ \\
\hline Gender (\% female) & 100 & 88.3 \\
\hline $\begin{array}{l}\text { Age (mean } \pm \text { S.D.) } \\
\text { (range) (years) }\end{array}$ & $\begin{array}{l}42.6 \pm 17.0 \\
(16-93)\end{array}$ & $\begin{array}{l}46.9 \pm 18.6 \\
(16-93)\end{array}$ \\
\hline $15-65$ & $141(82.0)$ & $248(74.3)$ \\
\hline$>65$ & $25(14.0) *$ & $70(20.9)$ \\
\hline Missing & $7(4.0)$ & $16(4.8)$ \\
\hline $\begin{array}{l}\text { History of previous UTI } \\
\text { in the last } 2 \text { weeks }\end{array}$ & $0^{\mathrm{a}}$ & $13(3.9)$ \\
\hline $\begin{array}{l}\text { History of admission } \\
\text { in the last year }\end{array}$ & $11(6.4) *$ & $39(11.7)$ \\
\hline $\begin{array}{l}\text { History of urinary catheter } \\
\text { placement during admission }\end{array}$ & $7(4.1)$ & $18(5.4)$ \\
\hline Diabetes mellitus & $0^{a}$ & $30(9.0)$ \\
\hline Nephrolithiasis & $0^{\mathrm{a}}$ & $27(8.1)$ \\
\hline Actively having a urinary catheter & $0^{a}$ & $15(4.5)$ \\
\hline Pregnancy & $0^{\mathrm{a}}$ & $6(1.8)$ \\
\hline History of UTI in the last 3 months & $16(9.3) *$ & $51(15.3)$ \\
\hline History of UTI in the past & $64(37.2)$ & $122(36.5)$ \\
\hline $\begin{array}{l}\text { History of receiving an antibiotic } \\
\text { in the last } 3 \text { months for } \\
\text { reason other than UTI }\end{array}$ & $33(19.2)$ & $62(18.6)$ \\
\hline
\end{tabular}

AUC acute uncomplicated cystitis, S.D. standard deviation, UT/ urinary tract infection.

${ }^{\text {a }}$ Not applicable by protocol definition. ${ }^{*} \mathrm{P} \leq 0.05$.

lactamases and penicillinase production or hyperproduction) were detected by phenotypic analysis and interpretation following the EUCAST guidelines [15].

\section{Definitions}

Male gender, pregnancy, history of urinary tract infection in the last two weeks, history of admission to the hospital in the last 30 days, the presence of diabetes mellitus or nephrolithiasis and the presence of a urinary catheter on sampling were considered as complicating factors [10].

Female non pregnant patients, without complicating factors, presenting with at least one urinary symptom (i.e. frequency, dysuria, hematuria, suprapubic pain, excluding fever and vaginal symptoms), and a positive urine culture were assigned to the group "Acute Uncomplicated Cystitis" (AUC) [3].

\section{Statistical analysis}

In the univariate analysis proportions of NS (non susceptible) or R (resistant) strains between categorical variables were compared using the Pearson's chi-square test or the Fischer's exact test where appropriate. A pvalue $<0.05$ was considered as statistically significant.
Univariate predictors with $\mathrm{p}<0.1$ were tested for inclusion in a step-wise multivariate model. Nonsignificant variables were removed sequentially until only those significant at $\mathrm{p}<0.1$ remained. The analysis was carried out using Stata 10.0 (Stata Corp, Texas, USA).

\section{Results}

\section{Demographic analysis}

Cefditoren was studied against a total of 563 isolates (330 E. coli, 142 Proteus mirabilis and 91 Klebsiella spp-three $K$. oxytoca and $88 K$. pneumoniae). Fully evaluable clinical information was available for $334 / 563$ isolates (59.3\%), i.e. 214/330 E. coli (64.8\%), 75/142 P. mirabilis (52.8\%) and 45/91 Klebsiella spp (49.5\%). Women accounted for $88.3 \%$ of the patients with a mean age of 45.8 years $(\mathrm{SD} \pm 18.5 \mathrm{ys})$. A total of 318 cases of acute uncomplicated cystitis were available for evaluation. Demographic and clinical data are listed in detail in Table 1.

\section{Antimicrobial susceptibility testing for the total sample population}

The in vitro activity of the antimicrobial agents tested against all the isolates in the study are listed in detail in

Table 2 Non-susceptibility ${ }^{a}$ rates (\%) for the total isolate yield of the study $(n=563)$

\begin{tabular}{|c|c|c|c|}
\hline Antimicrobial agent & $\begin{array}{l}\text { Escherichia coli } \\
\quad(n=330)\end{array}$ & $\begin{array}{l}\text { Klebsiella spp } \\
\quad(n=91)\end{array}$ & $\begin{array}{l}\text { Proteus } \\
\text { mirabilis } \\
(n=142)\end{array}$ \\
\hline Amoxicillin & 31.5 & $N / A^{b}$ & 33.1 \\
\hline Amoxicillin/clavulanic acid & 6.4 & 1.1 & 4.2 \\
\hline Cefalothin & 9.1 & 3.3 & 13.4 \\
\hline Cefuroxime sodium & 2.7 & 1.1 & 1.4 \\
\hline Cefuroxime axetil & 3.9 & 3.3 & 2.8 \\
\hline Co-trimoxazole & 23.6 & 11.0 & 13.4 \\
\hline Nalidixic acid & 8.2 & 9.9 & 5.6 \\
\hline Ciprofloxacin & 4.8 & 5.5 & 1.4 \\
\hline Mecillinam & 3.6 & 1.1 & 22.5 \\
\hline Nitrofurantoin & 6.4 & 30.8 & $N / A^{b}$ \\
\hline Fosfomycin $^{c}$ & 1.2 & 1.1 & 9.9 \\
\hline Cefotaxime & 3.0 & 1.1 & 1.4 \\
\hline Ceftazidime & 0.6 & 1.1 & 3.5 \\
\hline Gentamicin & 2.1 & 1.1 & 4.2 \\
\hline Netilimicin & 0.6 & 1.1 & 0.7 \\
\hline Amikacin & 0.9 & 1.1 & 0 \\
\hline Piperacillin-tazobactam & 0.6 & 1.1 & 0 \\
\hline Ticarcillin-clavulanate & 0.9 & 1.1 & 0.7 \\
\hline Imipenem & 0.6 & 0 & 0.7 \\
\hline Cefditoren & 3.0 & 3.3 & 2.1 \\
\hline
\end{tabular}

${ }^{a}$ CLSI 2011 breakpoints of susceptibility were applied.

${ }^{b} \mathrm{~N} / \mathrm{A}$ : not applicable (species inherently resistant).

c Fosfomycin trometamol is no long marketed in Greece. 
Table 2, in terms of non-susceptibility rates (intermediate resistance and resistance rates). Cefditoren nonsusceptibility rates for E. coli, P. mirabilis and Klebsiella spp were 10/330 (3\%), 3/142 (2.1\%), and 3/91 (3.3\%) respectively, while respective values for MIC50/MIC90 were $0.25 / 0.50,0.125 / 0.25$, and $0.25 / 0.5 \mathrm{mg} / \mathrm{L}$ (in total $0.25 / 0.5 \mathrm{mg} / \mathrm{L}$, range $0.03-128 \mathrm{mg} / \mathrm{L}$ ). In Figure 1 , MIC distribution for cefditoren against all isolates of $E$. coli, P. mirabilis and Klebsiella spp is displayed.

Phenotypic identification of ESBL production was evident in 9 strains (8 E coli, 1 Klebsiella spp), while plasmid-mediated Amp-C in 3 strains (3 P. mirabilis). Production of inhibitor-resistant TEM $\beta$-lactamases and penicillinase production/hyperproduction was identified in 11 strains (9 E coli, 2 Klebsiella spp). All ESBLproducer strains were resistant to cefditoren (MIC range 16-128 $\mathrm{mg} / \mathrm{L}$ ); the same applied for all three plasmidic AmpC producers possessing MIC of cefditoren at $64 \mathrm{mg} / \mathrm{L}$. TEM/hyperproducers displayed more variable MICs against cefditoren; in 7/11 the MIC was equal to $1 \mathrm{mg} / \mathrm{L}$, whereas it ranged between $2-4 \mathrm{mg} / \mathrm{L}$ for the 4 remaining strains of this kind.

Cefditoren displayed good in vitro activity against E. coli isolates with different mechanisms of resistance. For ampicillin non-susceptible strains (104 strains) cefditoren MIC50/MIC90 values were $0.25 / 1 \mathrm{mg} / \mathrm{L}$, whereas for amoxicillin-clavulanate and ciprofloxacin non-susceptible strains (21 and 16 strains respectively) the respective values were $0.5 / 128 \mathrm{mg} / \mathrm{L}$. Finally, cefditoren MIC50/MIC90 values of cotrimoxazole nonsusceptible strains $(\mathrm{n}=78)$ were $0.25 / 4 \mathrm{mg} / \mathrm{L}$.

\section{Antimicrobial susceptibility testing for the study population with available clinical data}

Non-susceptibility rates for $E$. coli isolates from AUC cases are listed in Table 3. MIC50/90 for cefditoren were $0.25 / 0.50 \mathrm{mg} / \mathrm{L}$ for AUC $E$ coli isolates. Nonsusceptibility rates for Proteus mirabilis and Klebsiella spp. isolates from AUC cases are listed in Table 4;
Table 3 Escherichia coli non-susceptibility rates ${ }^{a}$ for cases with available clinical data

\begin{tabular}{|c|c|c|}
\hline Antimicrobial agent & $\begin{array}{l}\text { AUC } \\
(n=119)\end{array}$ & $\begin{array}{l}\text { Total } E \text {. coli cases with } \\
\text { available clinical info } \\
(n=214)\end{array}$ \\
\hline Amoxicillin & 26.1 & 27.6 \\
\hline Amoxicillin/clavulanic acid & 5.0 & 4.7 \\
\hline Cefalothin & 6.7 & 7.9 \\
\hline Cefuroxime sodium ${ }^{b}$ & 0.8 & 1.4 \\
\hline Cefuroxime axetil ${ }^{c}$ & 2.5 & 3.3 \\
\hline Co-trimoxazole & 18.5 & 18.7 \\
\hline Nalidixic acid & 5.0 & 7.9 \\
\hline Ciprofloxacin & 1.7 & 4.2 \\
\hline Mecillinam & 2.5 & 2.8 \\
\hline Nitrofurantoin & 7.6 & 7.0 \\
\hline Fosfomycin ${ }^{d}$ & 0 & 0.5 \\
\hline Cefotaxime & 0.8 & 2.3 \\
\hline Ceftazidime & 0 & 0 \\
\hline Gentamicin & 0 & 1.4 \\
\hline Netilimicin & 0 & 0.5 \\
\hline Amikacin & 0 & 0 \\
\hline Piperacillin-tazobactam & 0 & 0 \\
\hline Ticarcillin-clavulanate & 0.8 & 0.9 \\
\hline Imipenem & 0 & 0 \\
\hline Cefditoren & 1.7 & 1.9 \\
\hline
\end{tabular}

AUC. acute uncomplicated cystitis; ${ }^{\text {a }}$ CLSI 2011 breakpoints of susceptibility were applied; ${ }^{b}$ Results reported according to the breakpoint of parenteral cefuroxime; ${ }^{\mathrm{C}}$ Results reported according to the breakpoint of oral cefuroxime; ${ }^{d}$ Fosfomycin trometamol is no long marketed in Greece.

MIC50/90 values for cefditoren were $0.125 / 0.25$ and $0.125 / 0.25 \mathrm{mg} / \mathrm{L}$ respectively.

\section{Risk factors for cefditoren non-susceptibility}

In the total isolates yield (563 strains), cefditoren non-susceptibility was positively associated with the

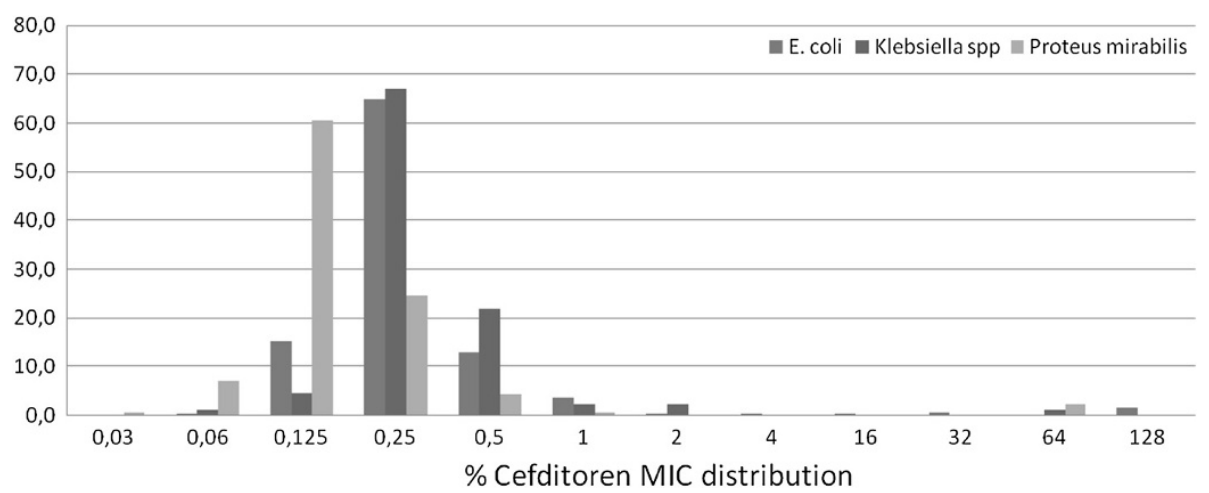

Figure 1 Cefditoren (\%) MIC distribution per species. 
Table 4 Proteus mirabilis. and Klebsiella spp non-susceptibility rates ${ }^{a}$ for cases with available clinical data

\begin{tabular}{|c|c|c|c|c|}
\hline \multirow[t]{2}{*}{ Antimicrobial agent } & \multicolumn{2}{|c|}{ Proteus mirabilis } & \multicolumn{2}{|c|}{ Klebsiella spp. } \\
\hline & $\operatorname{AUC}^{b}(n=31)$ & $\begin{array}{l}\text { Total cases with } \\
\text { available clinical } \\
\text { information }(n=75)\end{array}$ & $\operatorname{AUC}^{b}(n=22)$ & $\begin{array}{l}\text { Total cases with } \\
\text { available clinical } \\
\text { information }(n=45)\end{array}$ \\
\hline Amoxicillin & 35.5 & 33.3 & $\mathrm{~N} / \mathrm{A}^{\mathrm{c}}$ & $N / A^{c}$ \\
\hline $\begin{array}{l}\text { Amoxicillin/ } \\
\text { clavulanic acid }\end{array}$ & 6.5 & 5.3 & 0 & 2.2 \\
\hline Cefalothin & 12.9 & 12.0 & 4.5 & 4.4 \\
\hline $\begin{array}{l}\text { Cefuroxime } \\
\text { sodium }\end{array}$ & 0 & 2.7 & 0 & 0 \\
\hline Cefuroxime axetil & 3.2 & 5.3 & 4.5 & 2.2 \\
\hline Co-trimoxazole & 16.1 & 16 & 9.1 & 11.1 \\
\hline Nalidixic acid & 9.7 & 6.7 & $0^{*}$ & 8.9 \\
\hline Ciprofloxacin & 6.5 & 2.7 & 0 & 4.4 \\
\hline Mecillinam & 25.8 & 21.3 & 0 & 0 \\
\hline Nitrofurantoin & $N / A^{c}$ & $N / A^{c}$ & 40.9 & 33.3 \\
\hline Fosfomycin & 0 & 0 & 0 & 2.2 \\
\hline Cefotaxime & 3.2 & 3.2 & 0 & 0 \\
\hline Ceftazidime & 6.5 & 5.3 & 0 & 0 \\
\hline Gentamicin & 0 & 2.7 & 0 & \\
\hline Netilimicin & 0 & 0 & 0 & 2.2 \\
\hline Amikacin & 0 & 0 & 4.5 & 4.4 \\
\hline $\begin{array}{l}\text { Piperacillin- } \\
\text { tazobactam }\end{array}$ & 0 & 0 & 0 & 0 \\
\hline $\begin{array}{l}\text { Ticarcillin- } \\
\text { clavulanate }\end{array}$ & 0 & 0 & 0 & 0 \\
\hline Imipenem & 0 & 0 & 0 & 0 \\
\hline Cefditoren & 3.2 & 2.7 & 0 & 2.2 \\
\hline
\end{tabular}

${ }^{\mathrm{a}}$ CLSI 2011 breakpoints of susceptibility were applied; ${ }^{\mathrm{b}}$ Acute Uncomplicated Cystitis, ${ }^{\mathrm{c}}$ not applicable, , ${ }^{*} \mathrm{P} \leq 0.05$.

co-existence of non-susceptibility to other antimicrobials, with the exceptions of mecillinam, imipenem, fosfomycin, nitrofurantoin, gentamicin and netilmicin. Cefditoren MIC was significantly higher in nalidixic/ ciprofloxacin non-susceptible strains. The same applied for ciprofloxacin MIC in cefditoren non-susceptible isolates (Table 5). These results were also true for the subgroup of isolates with available clinical information (data not shown). Univariate analysis of clinical information has demonstrated the following risk factors associated with Cefditoren non-susceptibility: the presence of fever $(\mathrm{P}=0.016)$, history of urinary tract infection in the previous two weeks from sampling $(P=0.026)$, history of urinary tract infection in the previous three months $(\mathrm{P}=0.012)$, use of a fluoroquinolone during the previous three months $(\mathrm{P}=0.018)$ and use of a cephalosporin or a clavulanate fixed combination in the previous three months $(P=0.042)$. In the multivariate analysis only history of urinary tract infection in the previous two weeks and in the previous three months retained

Table 5 MIC50/90 distribution according to different resistance phenotypes

\begin{tabular}{|c|c|c|c|}
\hline & Cefditoren susceptible strains & Cefditoren non-susceptible strains & $P$ \\
\hline \multirow[t]{2}{*}{ Ciprofloxacin MIC50/MIC90 (mg/L) } & $0.012 / 0.032$ & $0.19 / 32$ & $<0.001$ \\
\hline & Nalidixic acid susceptible strains & Nalidixic acid non-susceptible strains & P \\
\hline \multirow[t]{2}{*}{ Cefditoren MIC50/MIC90 (mg/L) } & $0.25 / 0.5$ & $0.25 / 48$ & $<0.001$ \\
\hline & Ciprofloxacin susceptible strains & Ciprofloxacin non-susceptible strains & $P$ \\
\hline Cefditoren MIC50/MIC90 (mg/L) & $0.25 / 0.5$ & $0.5 / 64$ & $<0.001$ \\
\hline
\end{tabular}


Table 6 Multivariate analysis of risk factors for cefditoren resistance

\begin{tabular}{lccc}
\hline Parameter & $\boldsymbol{p}$ value & Odds Ratio & 95\% Confidence Interval \\
\hline Presence of fever & 0.14 & 5.69 & $0.58-55.54$ \\
History of UTI in the previous 2 weeks & 0.006 & 39.65 & $2.88-546.30$ \\
History of UTI in the previous 3 months & 0.04 & 22.67 & $1.12-457.48$ \\
Fluoroquinolone use in the last 3 months & 0.32 & 0.16 & $0.04-5.89$ \\
Cephalosporin or clavulanate fixed combination in the last 3 months & 0.86 & 0.78 & $0.05-11.48$ \\
\hline
\end{tabular}

UTI urinary tract infection.

statistical significance (Table 6). Clinical and microbiological charecteristics of isolates with resistance in cefditoren are listed in Table 7.

\section{Discussion}

Cefditoren is a rapidly bactericidal antibiotic as demonstrated by previous in vitro studies [7-9]. Clinical data on its use in urinary tract infections are currently lacking whereas microbiological data against uropathogens are scarce $[13,14]$. Currently there are not established susceptibility breakpoints for cefditoren against Gramnegative rods; for this reason we used as tentative breakpoint of susceptibility the threshold of $\leq 1 \mathrm{mg} / \mathrm{L}$, according to recently published evidence as well as the most recently proposed clinical breakpoints by EUCAST, setting susceptibility of the $3^{\text {rd }}$ generation cephalosporins against Enterobacteriaceae at $\leq 1 \mathrm{mg} / \mathrm{L}$ [13-15].

This is among the first studies which report antimicrobial susceptibility data of cefditoren in comparison to other commonly used antimicrobials from a large population-based surveillance study of outpatients with UTIs. According to the data presented herein, cefditoren had the lowest rate of resistance among the tested orally-available antibiotics after fosfomycin- which is not marketed in our country in the last 10 years. In vitro activity of cefditoren in our population of uropathogens was in accordance with data from Spain [14], whereas a study from Korea reported higher MIC90 (16 mg/L) compared to our data $(0.5 \mathrm{mg} / \mathrm{L})$ [13]. As reported previously, cefditoren was not active against ESBLproducing strains $[9,13]$, however its activity against TEM/hyperproducers was more variable compared to previous reports although the majority of the strains (63.6\%) were inhibited in clinically achievable concentrations [9].

Resistance to cefditoren was associated in our study with resistance to nalidixic acid- and resistance to ciprofloxacin. These observations are in accordance with data from Korea, a country with high levels resistance to ciprofloxacin among uropathogens $(30.3 \%$ in the study by Ko et al.) [13]. On the other hand, no association of resistance to cefditoren was found with mecillinam, fosfomycin, nitrofurantoin and aminoglycosides, indicating that their use as first line treatment options in community acquired UTIs as recommended by local guidelines would not affect the susceptibility of cefditoren. This observation was also confirmed in a recent large European multicenter study [17]. In both ECO.SENS studies, resistance to any antimicrobial studied was markedly higher in isolates resistant to any other antimicrobial, irrespective of whether or not the antibiotics belonged to the same class $[17,18]$. This has been partially attributed to a pool of resistance in aminopenicillins, folate inhibitors and fluoroquinolones among E.coli in the community and the long established plasmidmediated resistance to ampicillin and to trimethoprim/ sulfamethoxazole [17].

The accompanying questionnaire enabled us to classify UTIs as "complicated" or "uncomplicated" and to elucidate risk factors for resistance to cefditoren beyond the well-recognized use of an antibiotic of the same class in the previous 15 days- 3 months $[6,19,20]$. The presence of fever indicating complicated UTI, previous use of a cephalosporin or a fixed combination of clavulanate or a quinolone for any reason and recent history of UTI in the last two weeks and three months were elucidated in the univariate analysis as risk factors for cefditoren resistance; however only the history of UTI retained statistical significance in the multivariate analysis, with an Odds Ratio of 39.65 for the preceding two weeks and 22.67 for the preceding two months. Cephalosporins are not currently indicated as first line antibiotics in acute uncomplicated cystitis, not only because other classes of antibiotics provide more convenient schemes of treatment, but also for epidemiological reasons [3,21]. However, an emerging trend of resistance in cotrimoxazole is documented in several regions $[2,6,13,14]$. IDSA and several other national guidelines advise against the empirical use of cotrimoxazole in settings with known resistance above the threshold of $20 \%$ [3,20,21]. In our country, data acquired through a big population-based surveillance revealed a resistance rate of $19.2 \%$ for AUC E. coli strains [10]. According to these recently published data from our group, the most potent in vitro antibiotics available for oral use in AUC in our community were fosfomycin, mecillinam, cefuroxime axetil, ciprofloxacin and amoxicillin/clavulanic acid with resistance rates of 
Table 7 Microbiological and clinical information of Cefditoren-resistant isolates

\begin{tabular}{|c|c|c|c|c|c|c|c|c|c|c|c|c|c|c|c|c|c|c|c|c|c|}
\hline Isolate & MIC Cefdi & CIP & AN & AMC & AM & $\begin{array}{l}\text { Cefot } \\
\text { CTX }\end{array}$ & CAZ & $\begin{array}{l}\text { Cefur } \\
\text { CXM }\end{array}$ & Cefal CF & FOS & GM & IMP & MEC & NA & NET & FT & TZP & TCC & SXT & $\begin{array}{l}\text { Resistance } \\
\text { Phenotype }\end{array}$ & $\begin{array}{l}\text { Clinical details } \\
\text { available }\end{array}$ \\
\hline BA 356 E. coli & 1 & $\mathrm{~S}$ & $\mathrm{~S}$ & I & $R$ & $\mathrm{~S}$ & $\mathrm{~S}$ & $\mathrm{~S}$ & $\mathrm{~S}$ & $\mathrm{~s}$ & $\mathrm{~S}$ & $\mathrm{~S}$ & $\mathrm{~S}$ & $\mathrm{~S}$ & $\mathrm{~S}$ & $\mathrm{~S}$ & $\mathrm{~S}$ & $\mathrm{~S}$ & $\mathrm{~S}$ & TEM-1 hyperproduction & NA \\
\hline BA 425 E. coli & 1 & s & S & S & $\mathrm{R}$ & S & S & S & S & S & S & $S$ & S & S & S & S & $\mathrm{s}$ & S & $\mathrm{R}$ & TEM-1 + SXT & $\begin{array}{l}\text { 75ys female AUC, } \\
\text { doxycycline in the } \\
\text { last } 3 \text { mos }\end{array}$ \\
\hline BC 165 E. coli & 1 & S & S & $\mathrm{R}$ & $\mathrm{R}$ & S & S & S & R & S & S & $\mathrm{s}$ & S & S & S & $S$ & S & S & S & TEM-1 hyperproduction & $\begin{array}{l}25 y s \text { female UTI, } \\
\text { Hx of UTI in the } \\
\text { last } 2 \text { wks }\end{array}$ \\
\hline BC 211 E. coli & 1 & $\mathrm{R}$ & S & । & $\mathrm{R}$ & S & S & S & $\mathrm{R}$ & S & S & S & S & $\mathrm{R}$ & S & $S$ & $\mathrm{~s}$ & S & $\mathrm{R}$ & $\begin{array}{l}\text { TEM-1 hyperproduction + } \\
\text { SXT }+ \text { cross resistance } \\
\text { to all fluoroquinolones }\end{array}$ & $\begin{array}{l}\text { 81ys female AB with } \\
\text { diabetes mellitus and } \\
\text { nephrolithiasis, Hx of } \\
\text { UTI in the last } 2 \mathrm{ks} \\
\text { and } 3 \text { mos, use of CIP } \\
\text { in the last } 3 \text { mos }\end{array}$ \\
\hline BTH 486 E. coli & 1 & S & S & । & $\mathrm{R}$ & S & S & S & S & S & S & $\mathrm{s}$ & S & S & S & $\mathrm{s}$ & S & $\mathrm{S}$ & $\mathrm{R}$ & TEM-1 hyperproduction $+S X T^{R}$ & NA \\
\hline BM 538 E. coli & 1 & S & $\mathrm{s}$ & । & $\mathrm{R}$ & S & S & S & $\mathrm{R}$ & S & S & $\mathrm{s}$ & S & S & S & $\mathrm{S}$ & $\mathrm{s}$ & S & S & TEM-1 hyperproduction & NA \\
\hline PER 41ii E. coli & 1 & S & S & S & $\mathrm{R}$ & S & S & S & S & s & S & $S$ & S & S & S & $\mathrm{s}$ & $\mathrm{s}$ & S & S & TEM-1 & $\begin{array}{l}45 y \text { s male } A B, H x \text { of } \\
\text { UTI in the last year }\end{array}$ \\
\hline $\begin{array}{l}\text { BTH } 229 \\
\text { Klebsiella spp }\end{array}$ & 2 & S & S & S & $\mathrm{R}$ & S & S & S & $\mathrm{S}$ & S & S & $\mathrm{s}$ & S & S & S & । & $\mathrm{s}$ & S & $\mathrm{R}$ & SHV-1 natural $+\mathrm{FT}^{\mathrm{R}}+\mathrm{SXT}^{\mathrm{R}}$ & NA \\
\hline BP 129 E. coli & 2 & - & S & $\mathrm{R}$ & $\mathrm{R}$ & S & S & । & $\mathrm{R}$ & $\mathrm{R}$ & S & $\mathrm{S}$ & S & S & S & $\mathrm{R}$ & S & S & S & $\begin{array}{l}\text { TEM-1 hyperproduction + } \\
\mathrm{FT}^{R}+\mathrm{FOS}^{\mathrm{R}}\end{array}$ & NA \\
\hline $\begin{array}{l}\text { P } 72 \\
\text { Klebsiella spp }\end{array}$ & 2 & R & S & $\mathrm{s}$ & R & s & S & s & s & S & S & s & s & R & s & R & $\mathrm{s}$ & s & $\mathrm{R}$ & $\begin{array}{l}\mathrm{SHV}-1+\mathrm{FT}^{\mathrm{R}}+\mathrm{SXT}^{\mathrm{R}}+ \\
\text { cross resistance to all } \\
\text { fluoroquinolones }\end{array}$ & $\begin{array}{l}\text { 80ys female AB with } \\
\text { folley catheter, Hx of } \\
\text { UTI in the last } 2 \text { wks } \\
\text { and } 3 \text { mos, use of } \\
\text { cefaclor and TZP } \\
\text { in the last } 3 \text { months }\end{array}$ \\
\hline BK 319 E. coli & 4 & $\mathrm{R}$ & S & । & $\mathrm{R}$ & S & S & S & S & S & S & S & S & $\mathrm{R}$ & S & $\mathrm{S}$ & S & S & $\mathrm{R}$ & $\begin{array}{l}\text { TEM-1 hyperproduction + } \\
\text { SXT }^{R}+\text { cross resistance } \\
\text { to all fluoroquinolones }\end{array}$ & $\begin{array}{l}\text { 18ys female AUC, } \\
\text { Hx of UTI in the } \\
\text { last } 3 \text { mos }\end{array}$ \\
\hline BA 569 E. coli & 16 & S & S & S & R & $\mathrm{R}$ & s & $\mathrm{R}$ & R & S & s & S & s & S & s & S & S & S & $\mathrm{R}$ & ESBL CTX-type $+S X T^{R}$ & NA \\
\hline BTH 470 E. coli & 32 & S & S & S & $\mathrm{R}$ & $\mathrm{R}$ & $S$ & $\mathrm{R}$ & $\mathrm{R}$ & S & S & S & S & $\mathrm{R}$ & S & $S$ & $\mathrm{~s}$ & S & S & $\begin{array}{l}\text { ESBL CTX-type + Resistance } \\
\text { quinolones } \mathrm{Nal}^{\mathrm{R}}\end{array}$ & $\begin{array}{l}\text { 40ys female AUC, } \\
\text { Hx of UTI in the } \\
\text { last year }\end{array}$ \\
\hline BM 593 E. coli & 32 & s & S & S & R & R & S & R & R & S & s & $\mathrm{s}$ & s & R & s & s & $\mathrm{s}$ & s & $\mathrm{R}$ & $\begin{array}{l}\text { ESBL CTX-type }+\mathrm{SXT}^{R}+ \\
\text { Resistance quinolones } \mathrm{Nal}^{R}\end{array}$ & NA \\
\hline $\begin{array}{l}\text { BA } 524 \\
\text { Klebsiella spp }\end{array}$ & 64 & $\mathrm{R}$ & S & S & R & R & $\mathrm{R}$ & $\mathrm{R}$ & R & S & S & $\mathrm{s}$ & $\mathrm{R}$ & $\mathrm{R}$ & S & $\mathrm{s}$ & S & S & S & $\begin{array}{l}\text { ESBL + Mecilinam }{ }^{\mathrm{R}}+\text { Cross } \\
\text { resistance to all } \\
\text { fluoroquinolones }\end{array}$ & NA \\
\hline
\end{tabular}


Table 7 Microbiological and clinical information of Cefditoren-resistant isolates (Continued)

BM 463

P. mirabilis

$\begin{array}{lllllllll}64 & S & S & R & R & S & S & S & R\end{array}$

$S$ S S S S S

S R S

\title{
BM 465
}

P. mirabilis
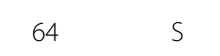

R

S

S S R

S

S

BM 466

64

P. mirabilis

BA 315 E. coli 128

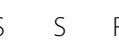

R S

S S R

R

$S S$

$S$

$\begin{array}{llllllll}S & S & R & R & R\end{array}$

R

$\begin{array}{ll}\text { GEM } 167 & 128 \\ \text { E. coli } & \\ \text { GEM } 250 & 128 \\ \text { E. coli } & \end{array}$

$\begin{array}{lll}S & S & \text { I } \\ R & S & S\end{array}$

$\begin{array}{ll}R & R \\ R & R\end{array}$

S

$R$
$R$

$\begin{array}{ll}S & S \\ S & S\end{array}$

$S$

$\begin{array}{lllll}S & S & S & S & S \\ R & S & S & S\end{array}$

$R$

\begin{abstract}
ESBL CTX-type + SXT
ESBL CTX-type + SXT $T^{R}+$
Cross resistance to al

fluoroquinolones ESBL CTX-type + SXT +
Resistance quinolones Nal

80ys female $A B$ with folley catheter, 3 mos, use of SXT and TZP in the last 3 mos, recent hospital admission foys female, dysuria-pyuria, use of cefaclor in the last 3 mos 36ys female AUC, last 3 mos and use of $\mathrm{CIP}$

NA

68ys female,

fever-pyuria, diabetes mellitus and nephrolithiasis, $\mathrm{Hx}$ of UTI in the Hx of UTI in the
last 2 wks and use of CIP, Hx of recent hospital admission

\begin{tabular}{|c|c|c|c|c|c|c|c|c|c|c|c|c|c|c|c|c|c|c|c|c|}
\hline $\begin{array}{l}\text { GEM } 315 \\
\text { E. coli }\end{array}$ & 128 & $S$ & $\mathrm{R}$ & S & $\mathrm{R}$ & $\mathrm{R}$ & $\mathrm{R}$ & $R$ & $\mathrm{R}$ & $\mathrm{R}$ & S & S & $\mathrm{R}$ & $S$ & S & $\mathrm{R}$ & 1 & S & $\mathrm{R}$ & $E S B L+S X T^{R}+F T^{R}+F O S^{R}$ \\
\hline TZ 250 E. coli & 128 & $\mathrm{R}$ & $\mathrm{R}$ & $\mathrm{R}$ & $\mathrm{R}$ & $\mathrm{R}$ & $\mathrm{R}$ & $\mathrm{R}$ & $\mathrm{R}$ & S & R & $\mathrm{R}$ & $\mathrm{R}$ & $\mathrm{R}$ & $\mathrm{R}$ & $\mathrm{R}$ & $\mathrm{R}$ & $\mathrm{R}$ & $\mathrm{R}$ & $\begin{array}{l}\text { MBL (XDR) + Cross resistance } \\
\text { to all fluoroquinolones }\end{array}$ \\
\hline
\end{tabular}

CIP: Ciprofloxacin, AN: Amikacin, AMC: Amoxicillin / clavulanic acid, AM: Ampicillin, CTX: Cefotaxime, CAZ: Ceftazidime, CXM: Cefuroxime, CF: Cephalothin, FOS: Fosfomycin, GM: Gentamicin, IMP: Imipenem, MEC Mecillinam, NA: Nalidixic acid, NET: Netilmicin, FT: Nitrofurantoin, TZP: Piperacillin / tazobactam, TCC: Ticarcillin / clavulanate, SXT: Trimethoprim / sulfamethoxazole. S: Sensitive, l:Intermediate susceptibility, R: Resistant, NA: not available, AUC: acute uncomplicated cystitis, CUTI: complicated urinary tract infection, AB: asymptomatic bacteriuria, Hx of UTI: history of urinary tract infection. 
$1.6 \%, 3.4 \%, 1.7 \%, 2.2 \%$ and $5.2 \%$ respectively. Interestingly, in this study cefditoren and oral cefuroxime displayed co-resistance only in isolates harboring ESBL or MBL mechanism of resistance (Table 7), although their overall susceptibility rates in the studied population were comparable ( $97.1 \%$ versus $94.1 \%$ respectively). Currently available data do not permit to adopt for cefuroxime the same risk factors elucidated for cefditoren but it is important to note that compared to other countries, cephalosporins of 2nd and 3rd generation and amoxicillin/ clavulanic acid retain susceptibility among common uropathogens in UTIs in our community $[2,10,17,18]$. As mentioned above, fosfomycin trometamol is no longer available in the Greek market. On the other side, collateral damage with the use of quinolones as well an alarming percentage of first step mutants among uropathogens in both uncomplicated (6\%) and complicated infections (12.7\%) [10] has prompted severe restriction policies against their indiscriminate use in the Greek community; this is also true in many countries [22,23]. Furthermore the between the ECO.SENS I (1999-2000) and ECO.SENS II (2007-2008) studies ciprofloxacin resistance almost doubled in Greece $[17,18]$, mandating quinolone sparing policies in our community.

A certain weakness of this study is the lack of clinical data for almost one third of the studied isolates. However the lack of significant differences in resistance rates against all antibiotics tested between the populations with and without clinical information, as well as the large and representative sample of our study argues in favor of an extended applicability of the conclusions in our community. Furthermore the addition of a pool of isolates without clinical data allowed for a simulation of real life treatment scenario of an outpatient with UTI. Another possible weakness is the lack of clinical therapeutic data, which would enable us to detect therapeutic failure in the community with currently used agents, but this was beyond the design and the scope of the current study.

Certainly no strong argument exists for the use of cefditoren as first line option in acute uncomplicated UTIs since other treatment options mentioned above retain good activity. However many UTIs treated in the community setting are not episodes of acute uncomplicated cystitis mandating concentrations in the upper urinary tract; patients are often pretreated with other first-line classes of antibiotics; apart from recent antibiotic use patients with complicated urinary tract infections treated as outpatients frequently bear risk factors for resistance to multiple classes of antibiotics [3,20]. Cefditoren could represent a treatment option in several cases among the above-mentioned patient/risk groups. According to our results, cefditoren could also be used in our community as a switch to oral treatment of patients with UTIs and risk factors for resistance to $1^{\text {st }}$ line options, initially treated with a parenteral antibiotic. A strong argument for the selection of cefditoren could be the lack of crossresistance with aminoglycosides, mecillinam, nitrofurantoin and fosfomycin.

\section{Conclusions}

In summary, cefditoren was the most potent in vitro antibiotic available for oral use in our country, against all three major pathogens causing UTIs in the outpatient setting. A potential was demonstrated for its use as empirical treatment in outpatients with no recent history of UTI, as an alternative to first line antimicrobials or in patients with risk factors for resistance to currently indicated first treatment options. Clinical studies are warranted to clearly define its possible role in the treatment of UTIs in outpatients.

\section{Competing interests}

All authors declared no competing interests related to this manuscript.

\section{Authors' contributions}

$\mathrm{DH}$ carried out the in vitro procedures and input of data, and helped to draft the manuscript. GP: Participated in the design of the study, drafting and refinement of the manuscript, interpretation of data and also carried out in vitro procedures. IK: Management of the database, input and evaluation of data, statistical analysis, drafting of the manuscript. NL: Carried out laboratory procedures with determination of in vitro susceptibilities and input of data. MS: Carried out laboratory procedures and evaluation of data. ID: Carried out laboratory procedures and evaluation of data. GKN: Performed the statistical analysis. EL: Carried out laboratory work and evaluation of in vitro data. HG: Conceived the study, participated in the study design, drafting and refinement of the manuscript and interpretation of data. All authors have read and approved the final manuscript.

\section{Author details}

'Department of Microbiology, "P. and A. Kyriakou" Children's Hospital, Thibon and Levadeias, 11527 Athens, Greece. ${ }^{2} 4$ th Department of Internal Medicine and Infectious Diseases Research Laboratory, Athens University School of Medicine, 1, Rimini St, 12462 Haidari, Athens, Greece. ${ }^{3}$ Department of Microbiology, "Laikon" General Hospital of Athens, 17 Agiou Thoma St, 11527 Athens, Greece. ${ }^{4}$ Hellenic Centre for Disease Control and Prevention, 3-5 Agrafon St, 15123 Maroussi, Athens, Greece. ${ }^{5} 6$ th Department of Internal Medicine, Hygeia Hospital, 4 Erythrou Stavrou st and Kifissias Ave, 15123 Maroussi, Athens, Greece.

Received: 10 March 2012 Accepted: 6 September 2012

Published: 25 September 2012

\section{References}

1. Ronald A: The etiology of urinary tract infection: traditional and emerging pathogens. Am J Med 2002, 113(Suppl 1A):14S-19S.

2. Naber KG, Schito G, Botto H, Palou J, Mazzei T: Surveillance study in Europe and Brazil on clinical aspects and Antimicrobial Resistance Epidemiology in Females with Cystitis (ARESC): implications for empiric therapy. Eur Urol 2008, 54:1164-1175.

3. Gupta K, Hooton TM, Naber KG, Wullt B, Colgan R, Miller RG, Moran GJ, Nicolle LE, Raz R, Schaeffer AJ, Soper DE: International Clinical Practice Guidelines for the Treatment of Acute Uncomplicated Cystitis and Pyelonephritis in Women: A 2010 Update by the Infectious Diseases Society of America and the European Society for Microbiology and Infectious Diseases. Clin Infect Dis 2011, 52:e103-e120.

4. Paterson DL: "Collateral damage" from cephalosporin or quinolone antibiotic therapy. Clin Infect Dis 2004, 38(Suppl. 4):S341-S345. 
5. Hillier S, Bell J, Heginbothom M, Roberts Z, Dunstan F, Howard A, Mason B, Butler CC: When do general practitioners request urine specimens for microbiology analysis? The applicability of antibiotic resistance surveillance based on routinely collected data. J Antimicrob Chemother 2006, 58:1303-1306.

6. Talan DA, Krishnadasan A, Abrahamian FM, Stamm WE, Moran GJ: Prevalence and risk factor analysis of trimethoprim-sulfamethoxazoleand fluoroquinolone-resistant Escherichia coli infection among emergency department patients with pyelonephritis. Clin Infect Dis 2008, 47:1150-1158.

7. Jones RN, Biedenbach DJ, Johnson DM: Cefditoren activity against nearly 1000 non-fastidious bacterial isolates and the development of in vitro susceptibility test methods. Diagn Microbiol Infect Dis 2000, 37:143-146.

8. Biedenbach DJ, Jones RN: Update of cefditoren activity tested against community-acquired pathogens associated with infections of the respiratory tract and skin and skin structures, including recent pharmacodynamic considerations. Diagn Microbiol Infect Dis 2009, 64:202-212.

9. Sevillano D, Aguilar L, Alou L, Giménez MJ, Torrico M, González N, Cafini F, Relaño MT, Coronel P, Prieto J: Urine bactericidal activity against Escherichia coli isolates exhibiting different resistance phenotypes/ genotypes in an in vitro pharmacodynamic model simulating urine concentrations obtained after oral administration of a 400-milligram single dose of cefditoren-pivoxil. Antimicrob Agents Chemother 2008, 52:1184-1186.

10. Katsarolis I, Poulakou G, Athanasia S, Kourea-Kremastinou J, Lambri N, Karaiskos E, Panagopoulos P, Kontopidou FV, Voutsinas D, Koratzanis G, Kanellopoulou M, Adamis G, Vagiakou H, Perdikaki P, Giamarellou H, Kanellakopoulou K: Collaborative Study Group on Antibiotic Resistance in Community-acquired Urinary Tract Infections: Acute uncomplicated cystitis: from surveillance data to a rationale for empirical treatment. Int J Antimicrob Agents 2010, 35:62-67.

11. Clinical and Laboratory Standards Institute: Performance Standards for Antimicrobial Susceptibility Testing. Wayne: CLSI; 2011. Twenty-First Informational Supplement, M100 - S21.

12. Darkes MJ, Plosker GL: Cefditoren pivoxil. Drugs 2002, 62:319-336.

13. Ko KS, Suh JY, Lee MY, Lee NY, Peck KR, Kwon KT, Jung DS, Song JH: In vitro activity of cefditoren against clinical isolates of Escherichia coli from a Korean hospital. Int J Antimicrob Agents 2007, 30:283-285.

14. Cuevas O, Cercenado E, Gimeno M, Marin M, Coronel P, Bouza E: Comparative in vitro activity of cefditoren and other antimicrobials against Enterobacteriaceae causing community-acquired uncomplicated urinary tract infections in women: a Spanish nationwide multicenter study. Diagn Microbiol Infect Dis 2010, 67:251-260.

15. European Committee on Antimicrobial Susceptibility Testing. available at: http://www.eucast.org/eucast_disk_diffusion_test/breakpoints/.

16. Tenover FC, Emery SL, Spiegel CA, Bradford PA, Eells S, Bonomo RA EA, McGowan JE Jr: Identification of plasmid-mediated AmpC betalactamases in Escherichia coli, Klebsiella spp. and Proteus species can potentially improve reporting of cephalosporin susceptibility testing results. J Clin Microbiol 2009, 47:294-299.

17. Kahlmeter $\mathrm{G}$, Poulsen $\mathrm{HO}$ : Antimicrobial susceptibility of Escherichia coli from community-acquired urinary tract infections in Europe: the ECO.SENS study revisited. Int J Antimicrob Agents 2012, 39:45-51.

18. Kahlmeter G, ECO.SENS: An international survey of the antimicrobial susceptibility of pathogens from uncomplicated urinary tract infections: the ECO.SENS Project. J Antimicrob Chemother 2003, 51:69-76.

19. Hillier S, Roberts Z, Dunstan F, Butler C, Howard A, Palmer S: Prior antibiotics and risk of antibiotic-resistant community-acquired urinary tract infection: a case-control study. J Antimicrob Chemother 2007, 60:92-99.

20. Hooton TM, Besser R, Foxman B, Fritsche TR, Nicolle LE: Acute uncomplicated cystitis in an era of increasing antibiotic resistance: a proposed approach to empirical therapy. Clin Infect Dis 2004, 39:75-80.

21. Guidelines for the Diagnosis and Empirical Treatment of Infections. Athens: Hellenic Center for the Disease Control and Prevention; 2007. available at http://www.keelpno.gr/Portals/Infections_Book.pdf.
22. Johnson L, Sabel A, Burman WJ, Everhart RM, Rome M, MacKenzie TD, Rozwadowski J, Mehler PS, Price CS: Emergence of fluoroquinolone resistance in outpatient urinary Escherichia coli isolates. Am J Med 2008, 121:876-884.

23. Quinolone Restriction Formulary implemented by the Hellenic Drug Administration (EOF). available at http://eof1.eof.gr/html/law.html.

doi:10.1186/1471-2334-12-228

Cite this article as: Hatzaki et al.: Cefditoren: Comparative efficacy with other antimicrobials and risk factors for resistance in clinical isolates causing UTIs in outpatients. BMC Infectious Diseases 2012 12:228.

\section{Submit your next manuscript to BioMed Central and take full advantage of:}

- Convenient online submission

- Thorough peer review

- No space constraints or color figure charges

- Immediate publication on acceptance

- Inclusion in PubMed, CAS, Scopus and Google Scholar

- Research which is freely available for redistribution

Submit your manuscript at www.biomedcentral.com/submit
C) Biomed Central 